
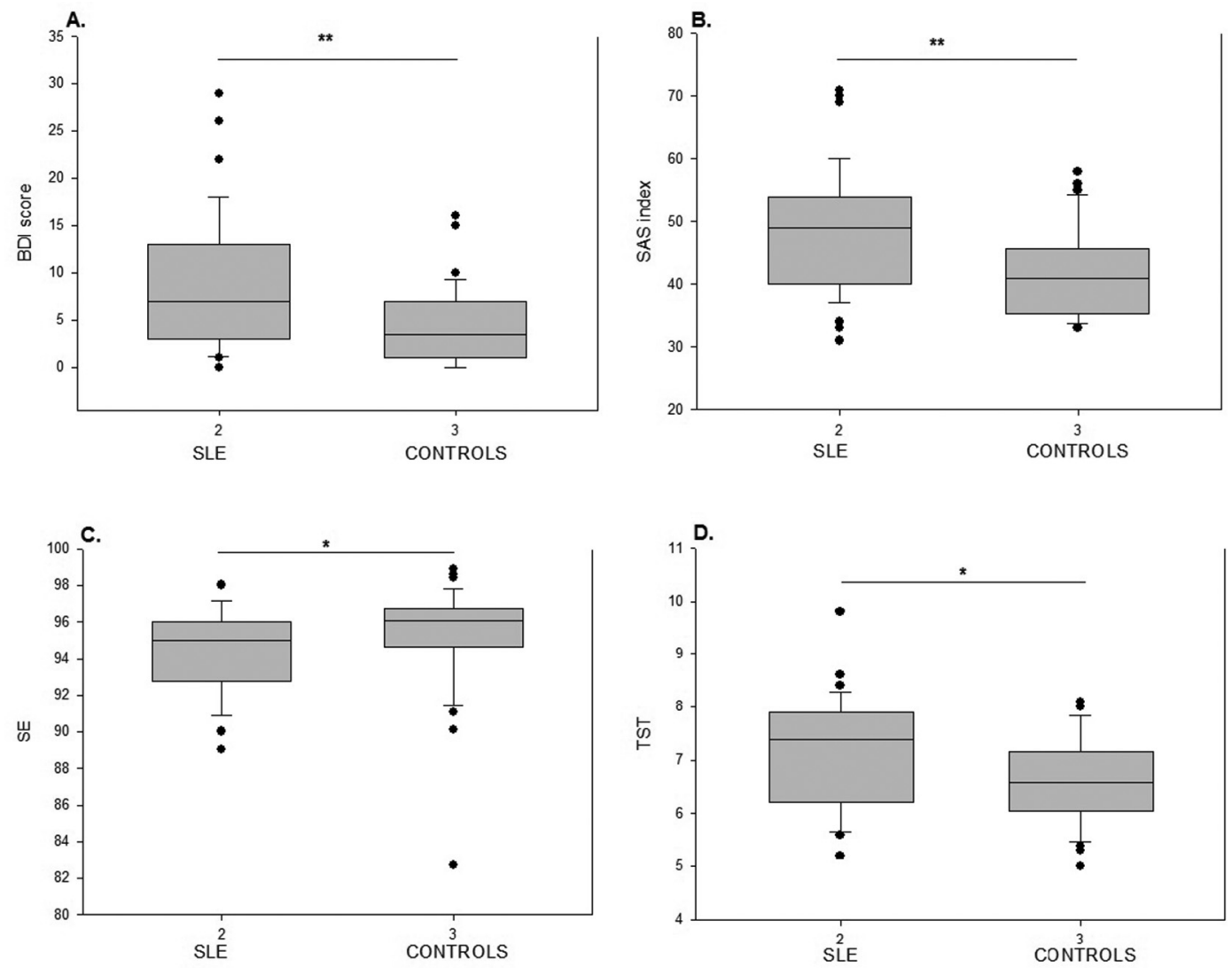

Abstract PS6:118 Figure 1 Comparison of beck depression inventory score (A), self rating anxiety scale index (B), sleep efficiency (C), total sleep time (D) between systemic lupus erythematosus group and controls. All these factors were significantly different between the two groups. MannWhitney rank sum test ${ }^{*}=p<0.05 ;{ }^{* *}=p<0.01$

\section{PS6:119 CLASS III-IV LUPUS NEPHRITIS MANAGEMENT IN EVERYDAY PRACTICE}

${ }^{1} \mathrm{~S}$ Porta, ${ }^{1} \mathrm{C}$ Aimo, ${ }^{1} \mathrm{M}$ Micelli, ${ }^{1} \mathrm{E}$ Kerzberg, ${ }^{2} \mathrm{G}$ Ruiz Irastorza. ${ }^{1}$ Rheumatology Department, Hospital J.M Ramos Mejía, Buenos Aires, ARGENTINA; ${ }^{2}$ Autoimmune Diseases Research Unit, Department of Internal Medicine, Hospital Universitario Cruces, The Basque Country, Spain

\subsection{6/lupus-2018-abstract.162}

Purpose To study the use in real life clinical practise of glucocorticoids (GCs), immunosuppressive and adjuvant therapy in Class III-IV Lupus Nephritis (LN).

Methods A multiple choice electronic questionnaire was sent to Latin American rheumatologists. Ten questions addressing the following topics: use of methylprednisolone pulses at the beginning of treatment and additionally during induction, use of oral GCs (maximum dose, tapering schedules, time on prednisone doses $>30 \mathrm{mg} /$ day, time until a prednisone dose of $5 \mathrm{mg} /$ day is reached); use of immunosuppressants during induction and maintenance therapies; and use of adjuvant therapies.

Results Were assessed 153 surveys (67 were from Argentina, 26 from Brazil, 12 from Venezuela, and 48 from Chile, Colombia, Cuba, Ecuador, Peru, Mexico and Costa Rica). As of GCs, 63.40\% (97/153) give three intravenous pulses of methylprednisolone of 1 gr, and then switch to $0.5-1 \mathrm{mg} / \mathrm{kg} / \mathrm{day}$ of oral prednisone. With the lack of a definite tapering scheme, 88.24\% (135/153) taper prednisone based on disease activity; $81.04 \%$ (124/153) maintain doses of oral prednisone $>30 \mathrm{mg} /$ day for 4 or more weeks and $40.42 \%$ (62/153) for 6 or more weeks; $43.79 \%$ (67/153) reach an oral prednisone dose of $5 \mathrm{mg} /$ day in 4 to 6 months, and $39.87 \%$
(61/153) in > 6 months; $79.08 \%(121 / 153)$ do not use additional intravenous pulses of methylprednisolone during induction.

Intravenous cyclophosphamide (IVCYC), $1 \mathrm{gr} / 4$ weeks, $(60.13 \%, 92 / 153)$ and mycophenolate mofetil (MFM) $(68.63 \%, 105 / 153)$ are the most used drugs for induction and maintenance treatment, respectively.

Regarding adjuvant therapy, 81.05\% (124/153) prescribe hydroxychloroquine in order to improve the prognosis of patients, and only $36.6 \%(56 / 153)$ consider it relevant to keep an adequate intake of calcium and vitamin D.

Conclusions In the real world therapy of LN, high doses of oral GCs are used during prolonged periods of time, with tapering schemes based on clinical response. Pulses of methylprednisolone are frequently given, but only at the beginning of the induction phase. IVCYC and MFM are the immunosuppressive drugs of choice for induction and maintenance therapy, respectively. Hydroxychloroquine frequently (but not universally) considered to improve the prognosis of these patients. Little attention is paid to calcium and vitamin D supplements.

\section{PS6:120 HAND ULTRASOUND GUIDED THERAPEUTIC DECISIONS IN INFLAMMATORY ARTHRITIS ASSOCIATED WITH SYSTEMIC LUPUS ERYTHEMATOSUS AND SJÖGREN'S SYNDROME}

${ }^{1} \mathrm{~L}$ Lei, ${ }^{1} \mathrm{~S}$ Morgan, ${ }^{2} \mathrm{E}$ Ntatsaki, ${ }^{2} \mathrm{C}$ Ciurtin. ${ }^{1}$ University College London Medical School, London, UK; ${ }^{2}$ University College London Hospital - Department of Rheumatology, London, UK

10.1136/lupus-2018-abstract.163 